\title{
Laparoscopic management of cervical and endometrial cancer in Africa: experience of the National Hospital Centre of Pikine
}

\author{
Moussa Diallo $^{1 *}$, Abdoul Aziz Diouf ${ }^{1}$, Aminata Niass $^{2}$, Astou Coly Niassy Diallo², \\ Cyr Esperence Gombet ${ }^{2}$, Magatte Mbaye $^{2}$, Babacar Biaye ${ }^{2}$, Sophie Coulbary ${ }^{3}$, Mori Niang ${ }^{3}$, \\ Codou Sene ${ }^{2}$, Anna Dia ${ }^{2}$, Alassane Diouf ${ }^{2}$
}

\begin{abstract}
${ }^{1}$ Gynecologist and Obstetrician, National Hospital of Pikine, Cheikh Anta DIOP of Dakar, Senegal
${ }^{2}$ Gynecologist and Obstetrician, National Hospital of Pikine, Dakar, Senegal

${ }^{3}$ Department of Anesthesia and Intensive Care, National Hospital of Pikine, Dakar, Senegal
\end{abstract}

Received: 16 May 2019

Revised: 14 September 2019

Accepted: 30 September 2019

\author{
*Correspondence: \\ Dr. Moussa Diallo, \\ E-mail: moussadiallo25@hotmail.com
}

Copyright: ( $)$ the author(s), publisher and licensee Medip Academy. This is an open-access article distributed under the terms of the Creative Commons Attribution Non-Commercial License, which permits unrestricted non-commercial use, distribution, and reproduction in any medium, provided the original work is properly cited.

\section{ABSTRACT}

Background: Laparotomy represents the standard historical surgical approach to these cancers. Process of treatment of benign adnexal pathologies to the emergence of a new pathway for the management of these cancerous pathologies.

Methods: Our prospective study from December 2016 to December 2018 included 10 patients with early-stage uterine cancer and endometrial cancer confirmed by MRI. The characteristics of patients, their cancer, their intervention and morbidity were revealed.

Results: Our results show that the average age of the patients was 63 years; There were 2 cases of cervical cancer and 8 cases of endometrial cancer. For cervical cancer, it was essentially squamous cell carcinoma; one patient was at stage Ia2 and the other at stage Ib1. For endometrial cancers, squamous cell carcinoma was $80 \%$; 6 patients were in stage IB and 2 in stage IC. Of the 10 patients undergoing surgery, 9 had laparoscopic colpohysterectomy and lymphadectomy and one complementary laparoscopic lymphadenectomy. The average number of lymph nodes removed was 9 and no lymph node metastasis was found. In the immediate postoperative period, one patient had transient urinary incontinence and another had vaginal slice lymphorhea.

Conclusions: The main interest of this practice is to be the least morbid possible for patients at the early stage. With our short experience, we obtained a reduction in operating time, a reduction in hospital stay, a decrease in the consumption of analgesics and antibiotics postoperatively and a reduction in per and postoperative complications.

Keywords: Cervical cancer, Endometrial cancer, Pelvic laparoscopy, Senegal

\section{INTRODUCTION}

Laparotomy remains the reference approach in cancer surgery in general. In the world and throughout developing countries, laparoscopy is increasingly taking on a role in the management of pelvic cancers, particularly cervical, endometrial and early ovarian cancers, as evidenced by the recommendations of learned societies. ${ }^{1,2}$ In Africa, although the late stages are always more important, the advent of this approach represents a real opportunity for cancers diagnosed in the early stage. Its contribution in terms of reducing morbidity and early 
recovery of women undergoing surgery are all advantages that can be beneficial for countries with limited resources. The progress of laparoscopic surgery, initially developed for the diagnosis and treatment of benign adnexal pathologies, has led to the emergence of a new approach for the management of these cancerous pathologies. ${ }^{3}$

Early stage cervical cancer (tumor size $<2 \mathrm{~cm}$ ) is a good prognosis and the major challenge in its management is to limit morbidity of treatment and, if possible, in some cases, preserve fertility while maintaining the same good carcinologic results. In many countries, we are witnessing more and more therapeutic de-escalation (surgical) and the profile of adjuvant treatments (radio and chemotherapy). It is in this perspective that laparoscopy has established itself not only as an approach, but also with new approaches (sentinel node, "nerve sparing"). ${ }^{4}$ Although it has proven its technical feasibility and oncological efficacy compared to laparotomy, no study to our knowledge has been done for its effective dissemination in our African reference centers. ${ }^{5.6}$

Thus, the aim of our study was to evaluate the place of laparoscopy in the surgical management of endometrial and cervical cancers at the National Hospital Centre of Pikine by analysing the indications, the surgical technique and the complications in order to develop this surgical technique.

We report here the preliminary results of a series of ten patients, including 3 cases of cervical cancer and 7 cases of endometrial cancer, all in the early stages.

\section{METHODS}

This was a prospective collection of all patients who received primary surgical management of cervical or endometrial cancer by the exclusive laparoscopic route from December 2016 to May 2019.

\section{Inclusion criteria}

- Included were all patients with early-stage cervical or endometrial cancer who were treated in Gynecology and Obstetrics at Pikine National Hospital.

\section{Exclusion criteria}

- Not included patients with cancer of the cervix or endometrium whose stage has not been clearly elucidated, - patients who had not continued their care in our structure, and - patients who had not had laparoscopic surgery.

\section{Preoperative evaluation}

After a histological diagnosis of cancer, magnetic resonance imaging (MRI) was performed for staging according to the International Federation of Gynecology and Obstetrics. Tumor size was measured. Its extension to parameters for cervical cancers and carefully estimated myometrial invasion. In addition, we were looking for the existence of pelvic or latero-aortic adenopathies.

The laparoscopic approach was decided following a consultation meeting. Patients were informed of the approach and the possibility of laparoconversion in case of major difficulty or complication. The interventions were performed by the same team, composed of surgeons with experience in the management of cancer by laparotomy.

All patients were clinically evaluated for size and uterine mobility parameters. The data were then recorded prospectively.

\section{Operating step}

Insufflation was done at the left hypochondrium or after umbilical incision, and the average insertion pressure of the trocars was $15 \mathrm{~mm} \mathrm{Hg}$. Abdominal and pelvic exploration was exhaustive and the assessment of uterine mobility was facilitated by the use of a locally designed uterine manipulator, which also allowed for better exposure of the vaginal fundus (Figure 3). After dissection of the ureter, the procedure always began with treatment of the lumbo-ovarian pedicles and round ligaments of the uterus. The approach to the cleaning area was done at the extension of the umbilical artery on the anterior pelvic wall; this allowed the cleaning area to be delimited (Figure 1).

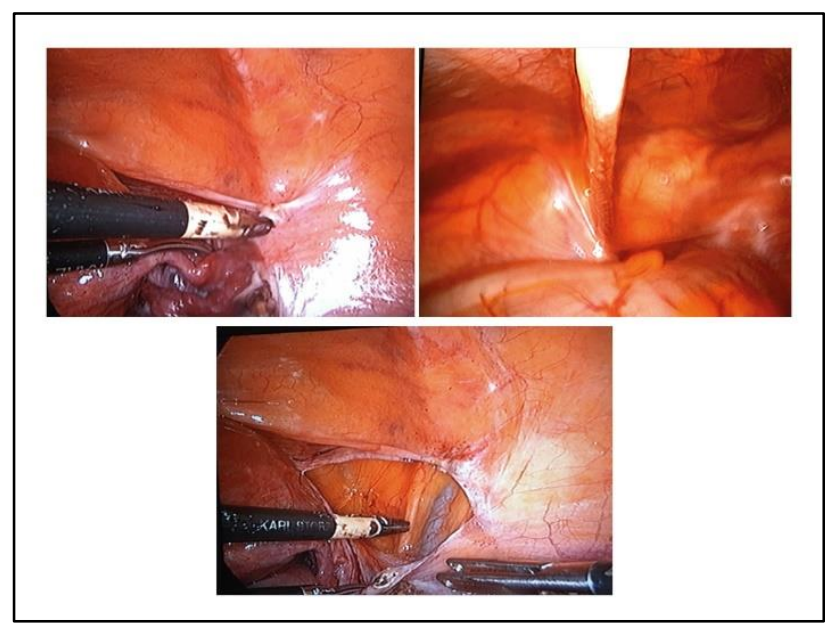

Figure 1: Image of the approach to lymphadenectomy by dissection of the umbilical artery: right side.

The rest of the dissection was continued as traditionally facilitated by the baro-dissection of carbon dioxide until an obviously complete cleaning was obtained (Figure 2). Then we continued the procedure with a total extrafascial hysterectomy with a sufficient vaginal collar using a canulator (Figures 3, 4 and 5). 


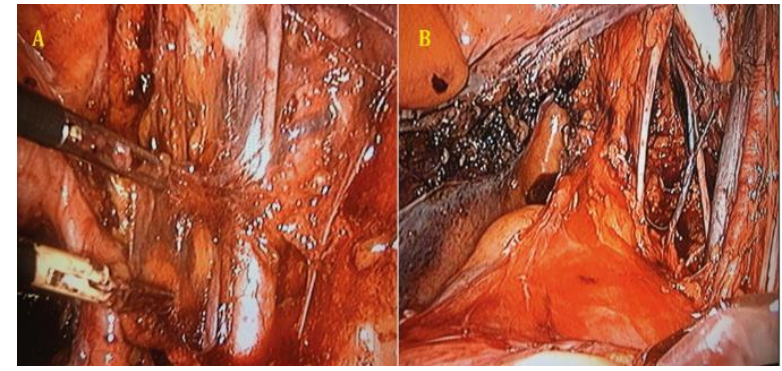

Figure 2: Pelvic lymph node dissection (A) and final view of the ilio-shutter cleaning area $(B)$ : right side.

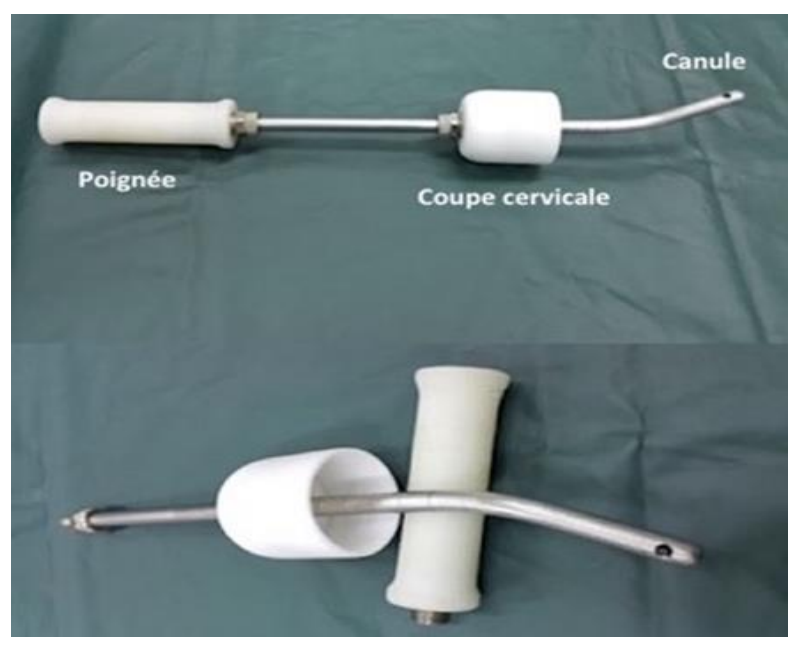

Figure 3: Uterine cannulator of local conception (Property of the Pikine Hospital).

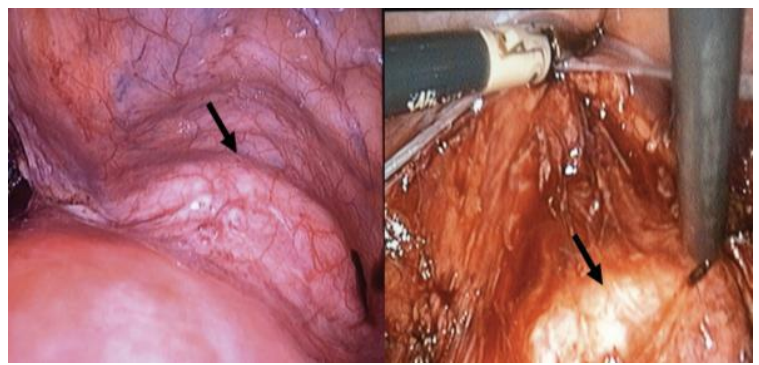

Figure 4: Exposure of the vagina (arrow) through the cannulator cup and incision.

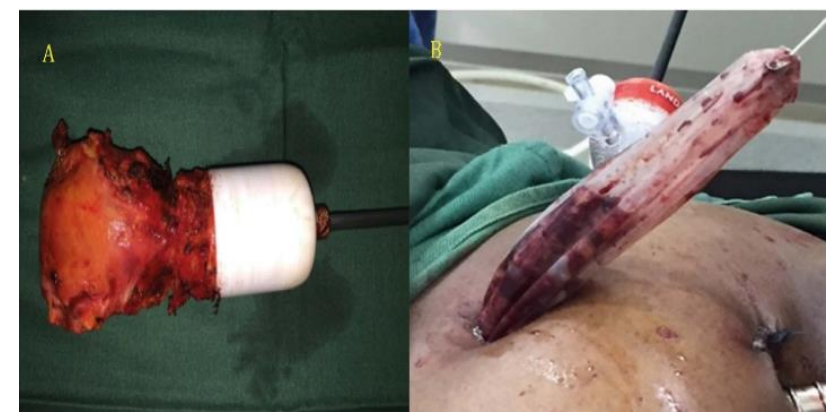

Figure 5: Removal of the cleaning specimen with an endoscopic bag (B) Removal of the uterus by the vaginal route $(A)$.

\section{Statistical analysis}

The data was entered and analyzed on the SPSS 23 software for Macintosh. We were mainly interested in the analysis of socio-demographic data, clinical characteristics, histological characteristics, surgical technique and complications of laparoscopy in the management of cervical and endometrial cancers.

\section{RESULTS}

\section{Socio-demographic characteristics}

The characteristics of our population are described in Table 1. The average age of the patients was 63 years with extremes of 50 and 75 years. The average gestité was 6 and the average parity was 4, the average weight was $76 \mathrm{~kg}$ with an average BMI of $31 \mathrm{~kg} / \mathrm{m}^{2}$. In the medical history, 3 patients were diabetic and $40 \%$ were known to have high blood pressure.

Table 1: Socio-demographic characteristics.

\begin{tabular}{|ll|}
\hline Patient characteristics & A verage \\
\hline Average age & 63 years \\
\hline Poids moyen & $76 \mathrm{~kg}$ \\
\hline Average BMI & $31 \mathrm{~kg} / \mathrm{m}^{2}$ \\
\hline Gestity & 6 \\
\hline Parity & 4 \\
\hline
\end{tabular}

\section{Clinical characteristics}

Among the 10 patients operated on, there were 2 cervical cancers and 8 endometrial cancers.

For patients with cervical cancer, one was at stage Ia2 and the other at stage Ib1.

For those with endometrial cancer, 6 of them were in stage Ia and 2 others in stage Ib of the International Federation of Gynecology and Obstetrics.

These different characteristics are summarized in Table 2.

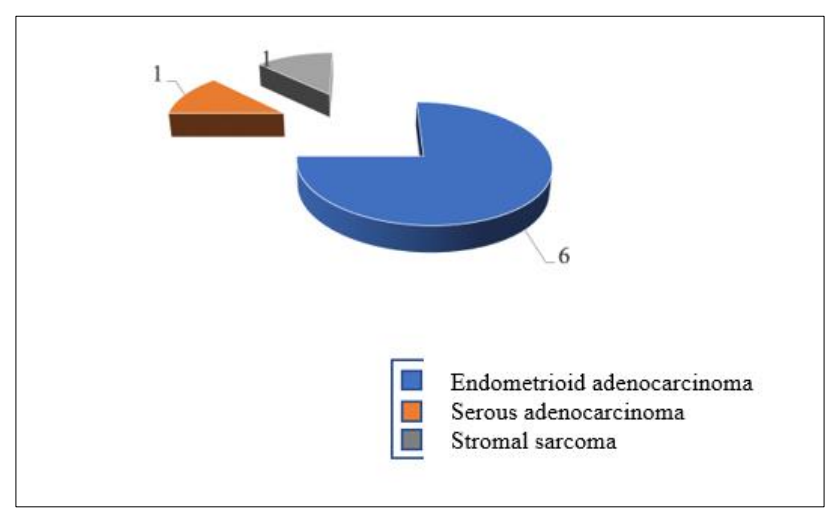

Figure 6: Endometrial cancer, distribution of histological types. 
Table 2: Clinical and histological characteristics.

\begin{tabular}{|c|c|c|c|c|}
\hline Patient characteristics & Cancer du col (2) & Cancer de l'end & re (8) & \\
\hline FIGO stage & Ia21 & Ia6 & $\mathrm{Ib} 2$ & \\
\hline Histology & $\begin{array}{l}\text { Squamous cell } \\
\text { carcinoma }\end{array}$ & $\begin{array}{l}\text { Endometroid } \\
\text { adenocarcinoma }\end{array}$ & $\begin{array}{l}\text { Serous } \\
\text { adenocarcinoma }\end{array}$ & $\begin{array}{l}\text { Endometrial stroma } \\
\text { sarcoma }\end{array}$ \\
\hline & & 6 & 1 & 1 \\
\hline Histological grade & Well differentiated & Low grade & Low grade & High grade \\
\hline
\end{tabular}

\section{Histological characteristics}

These characteristics are summarized in Table 2.

In patients with cervical cancer, it was essentially squamous cell carcinoma.

For those with endometrial cancer, essentially low-grade endometrioid adenocarcinoma was the most common histological type (Figure 6).

\section{Surgical characteristics}

Of the 10 patients operated on, 9 had a laparoscopic LHC and one had a complementary laparoscopic cleaning.

The laparoscopic approach was performed at the level of the left hypochondrium for the placement of the pneumoperitoneum for all patients, a $12 \mathrm{~mm}$ trocar for the optics at the umbilicus, two $5 \mathrm{~mm}$ trocars in the supraspinous region to the left of the patient for the main operator and another in the same region to the right for the main aid.

During the exploration, no secondary locations were found.

The average operating time was 168 minutes with extremes of 135 and 195 minutes; for an average cleaning time of 33 minutes per side.

Bilateral adnexectomy was performed in all patients. An average vaginal collar of $0.5 \mathrm{~cm}$ was obtained.

The average blood loss was estimated at $150 \mathrm{cc}$ with extremes of 100 and $320 \mathrm{cc}$.

An operating complication was observed in one patient. It was a $2 \mathrm{~cm}$ bladder wound whose suture had been done with simple sequelae.

For all patients, on histological examination, there was no post-operative residue. The number of lymph nodes in the cleaning product was 9 with extremes of 6 and 13. No lymph node metastasis had been found.

All operating procedures were entirely performed by laparoscopy.

\section{Post-operative surveillance}

In the immediate aftermath, patients received analgesic and non-steroidal anti-inflammatory treatment. This analgesic treatment was sufficient for all patients. Preventive treatment of venous thromboembolic disease was achieved with a single dose of low molecular weight heparin.

One patient (with cervical cancer) had transient incontinence-type urinary disorders for one week. These urinary disorders finally improved spontaneously; a performed uro-scanner had returned normal. A second patient had developed lymphorrhea through the vaginal slice. To date, none of our patients have shown any signs of local recurrence.

\section{DISCUSSION}

Laparoscopy allows most gynaecological procedures to be performed, both benign and cancerous. ${ }^{4,5}$ In gynaecology, we do not have enough randomized prospective trials. However, some clinical data show that the endoscopic approach may not be suitable for all clinical situations; although its efficacy has already been demonstrated in digestive surgery. ${ }^{4,7}$

Although innovative, these new techniques have not been the subject of formal recommendations in current practice; classical laparotomy still holds a prominent place for many operators, even well-trained ones. In Africa, the management of gynaecological cancers is almost exclusively by laparotomy and in Senegal, only our structure uses laparoscopy for gynaecological cancer surgery. ${ }^{8-10}$

These techniques pose the problem of their dissemination and teaching, which remain difficult because of the small number of cases encountered in daily practice under this approach. ${ }^{11-13}$

The implementation of increasingly effective screening methods and increasing access to quality care have led to an increase in early forms. A perfect illustration is mammography in breast cancer and cervico-vaginal smear in cervical cancer. ${ }^{1,3,12,14}$ 
At the same time, the therapeutic methods have undergone the same advances in terms of both the technology used and the approaches (vaginal and laparoscopic). ${ }^{3,15,16}$ The objective of these advances is to reduce the heavy morbidity associated with the management of cancer pathology, but also in considerable savings over the duration of the operation and hospital stay.

Canis et al, believe that laparoscopic treatment of tumours should be limited to early stage cervical cancers. Indeed, Nam et al, report a significantly higher recurrence rate in the group of patients who underwent radical vaginal hysterectomy assisted by laparoscopy (8.5\%) than in the laparotomy group $(2.5 \%) .{ }^{11,14}$ However, excluding 7 patients included in the laparoscopy group despite a tumour volume greater than $4.2 \mathrm{~cm}$ (a tumour of more than $2 \mathrm{~cm}$ is theoretically a contraindication to first laparoscopy), the recurrence rate of the laparoscopy group was only $2.5 \%$. In our series, we had no recurrence in the 2 patients with cervical cancer; these were precisely early stages (IA2 and IB1) of FIGO. Similarly, Uzan et al in their series found no recurrence in patients with a tumor size of less than $2 \mathrm{~cm} .^{1}$

Most comparative studies show that with laparoscopy there is less bleeding, longer hospital stay and longer operating time. Thus, Uzan et al obtained an average operating time of $280 \mathrm{~min}$, average blood loss of $150 \mathrm{cc}$ and a hospital stay of 5 days. ${ }^{1}$ Our results are therefore comparable to those in the literature for blood loss, however, in a short study period, we were able to obtain a reduction in the operating time for this type of intervention.

Our study shows an average number of 9 lymph nodes in the product of cleaning and complete resection on histological examination for all patients. Our results are satisfactory compared to those obtained by Uzan et al, where the average number of lymph nodes collected during a complete cleaning was 17 with $24.7 \%$ of patients with residual cervical disease. However, although this was also an early stage, the limited number of patients in our series prevents us from making a good comparison.

The data are more contradictory with regard to complication rates, particularly urinary complications and urinary difficulties. ${ }^{1}$ The first publications on laparoscopic treatment of endometrial cancer date from the early $1990 .^{2}$ Since then, several studies have suggested that the results obtained after laparoscopic treatment are equivalent to those obtained previously by laparotomy. ${ }^{14,17,18}$ However, there are still relatively few published studies and often few cases. Only one randomized prospective study, with 60 patients in each group, was published in 3 publications. ${ }^{11,19}$ The incidence of complications per and postoperatively was higher in the laparotomy group. A multivariate analysis shows that the surgical technique is the only factor that significantly influences the complication rate. ${ }^{20}$
In our series, we had a $2 \mathrm{~cm}$ bladder wound per operation; in early post-operative care, one patient had transient urinary incontinence for one week and another had lymphorrhea of the vaginal slice.

Eight intraoperative complications occurred in the study by Uzan et al. ${ }^{1}$ These were 4 bladder sores, 2 ureter lesions and 2 vessel lesions that required a blood transfusion during surgery. Early post-operative complications (within 90 days after surgery) were mainly symptomatic lymphocles, vaginal opening after intercourse, gutting and urinary complications (dysuria, ureteral fistula, ureteral stenosis).

Since the operator's experience is more important with laparotomy than with laparoscopy and the learning curve is much longer than is generally thought, the technical difficulties of extended hysterectomy by laparoscopy remain the main limitation to the dissemination of this technique. ${ }^{21}$

\section{CONCLUSION}

If the technique is rigorous, laparoscopy is an acceptable approach in the treatment of gynaecological cancers. It is still too little used for several reasons. Many oncology surgeons are convinced that the same thing can be done more easily and quickly by laparotomy, while in trained hands the operating times become similar to those of laparotomy. A perfect knowledge of surgical endoscopy and the rules of surgical oncology are essential prerequisites for the implementation of these techniques. The training of gynaecologic oncologist surgeons is an essential problem; it is complex even for laparotomy surgery.

The main interest of this practice is to be as morbid as possible for early-stage patients. With our short experience, we were able to obtain a reduction in the operating time of this type of intervention, the duration of the hospital stays and the post-operative consumption of analgesics and antibiotics.

\section{Funding: No funding sources Conflict of interest: None declared \\ Ethical approval: The study was approved by the Institutional Ethics Committee}

\section{REFERENCES}

1. Uzan C, Vincens E, Mazeron R, Balleyguier C, HaieMeder C, Morice P. Traitement des cancers du col de stade précoce. EMC-Gynécologie. 2010;5(2):1-13.

2. Bendifallah S, Canlorbe G. Prise en charge des tumeurs bénignes du sein épidémiologiquement fréquentes de type adénofibrome, phyllode (grade 1 et 2), et papillome: recommandations. J de Gynecol Obstét et Biol de la Reprod. 2015;44:1017-29. 
3. Childers JM, EA S. Combined laparoscopic vaginal surgery for the management of two cases of stage I endometrial cancer. Gynecol Oncol. 1992;45:46-51.

4. Roux CL, Sentilhes L, Catala L, Lefebvre-Lacoeuille C, Poilblanc M, Descamps P. Place of laparoscopy in the surgical treatment of cancers of the cervix, endometrium and ovary in France: results a national practice survey. J Phys Obstet Gynaecol Reprod Biol. 2011;40:231-6.

5. Colombo N, Carinelli S, Colombo A, Marini C, Rollo D, Sessa C. Cervical cancer: ESMO Clinical Practice Guidelines for diagnosis, treatment and follow-up. Ann Oncol. 2012;23(Supplement 7):vii27-vii32.

6. International Committee of the Red Cross. Press release $n^{\circ} 263.2018$.

7. Nam JH, Kim JH, DY K. Comparative study of laparospico-vaginal radical hysterectomy and abdominal radical hysterectomy in patients with early cervical cancer. Gynecol Oncol. 2004;92:27783.

8. Franklin ME, Kazantsev GB, Abrego D, Diaz-E JA, Balli J, JL G. Laparoscopy surgery for stage III colon cancer: long-term follow-up. Surg Endosc. 2000;14:612-6.

9. Guillonneau B, El-fettouh $\mathrm{H}$, Baumert $\mathrm{H}$, Cathelineau X, Doublet JD. Laparoscopic radical prostatectomy: oncological evaluation after 1,000 cases at Montsouris Institute. J Urol. 2003;169:12616.

10. Steed H, Rosen B, Murphy J, Laframboise S, Petrillo D, Covens A. A comparison of laparascopic-assisted radical vaginal hysterectomy and radical abdominal hysterectomy in the treatment of cervical cancer. Gynecol Oncol. 2004;93:588-93.

11. Hidlebaugh DA, RK O. Staging endometrioid adenocarcinoma. Clinical and financial comparison of laparoscopic and traditional approaches. J Reprod Med. 1997;42:482-8.

12. Lacy AM, Garcia-Valdecasas JC, Delgado S, Castells A, Taura P, JM P. Laparoscopy-assisted colectomy versus open colectomy for treatment of non-metastatic colon cancer: a randomized trial. Lancet. 2002;359:2224-9.
13. Canis M, Farina M, Jardon K, Rabischong B, Rivoire C, Nohuz E, et al. Cœlioscopie et cancer en gynécologie. J Gynecol Obstet Biol Reprod. 2005;35117-35.

14. Mage G, Bournazeau JA, Canis M, Glowaczower E, Masson FN. Treatment of endometrial clinical stage I adenocarcinoma by laparoscopy surgery. Seventeen cases. J Gynecol Obstet Biol Reprod. 1995;24:48590.

15. Malur S, Possover M, Michels W. Laparoscopicassisted vaginal versus abdominal surgery in patients with endometrial cancer: a prospective randomized trial. Gynecol Oncol. 2001;80:239-44.

16. NCCN. Guidelines Cervix cancer. NCCN Clinical Practice Guidelines in Oncology (NCCN Guidelines®). 2017;2017.

17. Occeli B, Samouelian V, Narducci F, Leblanc E. The choice of approach in surgical management of endometrial carcinoma: a retrospective serie of 155 cases. Bull Cancer. 2003;90:347-55.

18. Roberto T, Christhardt K, Alfonso F, Schneider A. Laparoscopic treatment of early ovarian cancer: surgical and survival outcomes. Gynecol Oncol. 2004;93:199-203.

19. Tozzi R, Malur S, Koehler C. Laparoscopy versus laparotomy in endometrial cancer: first analysis of survival of a randomized prospective study. J Minim Invasive Gynecol. 2005;12:130-6.

20. Trimbos JB, Hellebrekers BW, Kenter GG, Peters LA. The long learning curve of gynaecological cancer surgery: an argument for centralization. BJOG. 2000;17:19-23.

Cite this article as: Diallo M, Diouf AZ, Niass A, Diallo ACN, Gombet CE, Mbaye M, et al. Laparoscopic management of cervical and endometrial cancer in Africa: experience of the National Hospital Centre of Pikine. Int J Reprod Contracept Obstet Gynecol 2019;8:4429-34. 